\section{International Scientific Journal Theoretical \& Applied Science}

\author{
p-ISSN: 2308-4944 (print) e-ISSN: 2409-0085 (online) \\ Year: 2015 Issue: 05 Volume: 25
}

Published: $30.05 .2015 \quad$ http://T-Science.org
Gennady Evgenievich Markelov

Candidate of Engineering Sciences, associate professor,

Bauman Moscow State Technical University,

Moscow, Russia markelov@bmstu.ru

SECTION 21. Pedagogy. Psychology. Innovations in the field of education.

\title{
PARTICULAR ASPECTS OF TEACHING THE FUNDAMENTALS OF MATHEMATICAL MODELING
}

Abstract: This paper describes some particular aspects associated with teaching the Fundamentals of Mathematical Modeling. Taking into account these aspects allows improving the quality of graduates training and increasing their competitiveness.

Key words: mathematical modeling, information and communication technologies, individual approach, organization of training, quality training, competitiveness.

Language: Russian

Citation: Markelov GE (2015) PARTICULAR ASPECTS OF TEACHING THE FUNDAMENTALS OF MATHEMATICAL MODELING. ISJ Theoretical \& Applied Science 05 (25): 69-72.

Soi: http://s-o-i.org/1.1/TAS*05(25)14 Doi: crossef http://dx.doi.org/10.15863/TAS.2015.05.25.14

\section{ОСОБЕННОСТИ ПРЕПОДАВАНИЯ УЧЕБНОЙ ДИСЦИПЛИНЫ «ОСНОВЫ МАТЕМАТИЧЕСКОГО МОДЕЛИРОВАНИЯ»}

Аннотация: Изложены некоторые особенности, связанные с преподаванием учебной дисциилины «Основы математического моделирования». Учет таких особенностей позволяет улучшить качество подготовки выпускников, повысить их конкурентоспособность.

Ключевые слова: математическое моделирование, информаџионно-коммуникационные технологии, индивидуальный подход, организация обучения, качество подготовки, конкурентоспособность.

\section{Введение}

Математическое моделирование активно используют в таких наукоемких областях промышленности как машиностроение и приборостроение. Дальнейшее развитие этих областей требует высококвалифицированных специалистов, которые обладают необходимыми профессиональными качествами и могут решать возникающие научно-технические задачи, рационально используя возможности математического моделирования. В этой связи становится важным преподавание основ математического моделирования, направленное на изучение современных методов построения математических моделей, способов качественного и количественного анализа математических моделей, методик, позволяющих рационально использовать возможности математического моделирования в области машиностроения и приборостроения.

Целью настоящей работы является изложение некоторых важных особенностей, связанных с преподаванием учебной дисциплины «Основы математического моделирования» в МГТУ имени Н.Э. Баумана. Учет таких особенностей улучшает качество подготовки выпускников к профессиональной деятельности в области машиностроения и приборостроения, повышает их конкурентоспособность.

\section{Содержание и структура учебной дисциплины}

При разработке содержания и структуры учебной дисциплины «Основы математического моделирования» особого внимания заслуживают рекомендации, приведенные в работе [1].

\section{Единый подход к построению} математических моделей

Возможности

математического моделирования, подробно рассмотренные, например, в работах [2-9], часто не используют рационально из-за того, что математическая 
модель исследуемого объекта не обладает нужными свойствами.

Разработка математической модели, в достаточной мере обладающей нужными свойствами применительно к конкретному исследованию, предполагает выполнение соответствующих требований, предъявляемых к математической модели. Эти требования противоречивы и на практике могут быть удовлетворены лишь на основе разумного компромисса.

Для построения таких моделей следует выполнять правила и рекомендации, которые стали итогом обобщения накопленного практического опыта разработки математических моделей. При отсутствии богатого практического опыта построения моделей особый интерес представляют принципы построения математических моделей, которые носят общий и универсальный характер. Так, например, в работе [10] сформулированы принципы, разумное использование которых в совокупности позволяет реализовать единый подход к построению математической модели, в достаточной мере обладающей нужными свойствами применительно к конкретному исследованию. Пример построения такой модели подробно изложен в работе [11].

Как показывает практика, единый подход к построению математических моделей является перспективным и заслуживает детального рассмотрения.

\section{Информационно-коммуникационные технологии}

Сейчас объем аудиторных учебных занятий по дисциплине «Основы математического моделирования» уменьшен, а существенная часть материала дисциплины отведена на самостоятельную проработку. Это затрудняет использование традиционных методов обучения, когда преподаватель вынужден тратить много времени на написание формул и создание рисунков с помощью доски и мела, и приводит к необходимости внедрения информационнокоммуникационных технологий в учебный процесс.

Внедрение информационнокоммуникационных технологий предполагает обеспечение учебного процесса следующими электронными материалами по дисциплине «Основы математического моделирования»:

$\checkmark$ учебно-теоретическими изданиями, например, учебником, учебными пособиями, курсом лекций, конспектом лекций;

$\checkmark$ учебно-практическими изданиями, например, задачником, сборником упражнений, сборником контрольных заданий, сборником заданий для самопроверки;

$\checkmark$ учебно-методическими изданиями, например, учебно-методическими пособиями, методическими рекомендациями и указаниями;

$\checkmark$ учебно-справочными изданиями, например, учебным терминологическим словарем, учебным справочником;

$\checkmark$ другими необходимыми материалами, например, мультимедийными презентациями, интерактивными вебприложениями.

Студентам также следует предоставлять электронные средства обучения, возможность самотестирования и получения консультаций в онлайн-режиме.

Изучение дисциплины «Основы математического моделирования» связано с необходимостью усвоения материала, сопровождающегося разнообразными понятиями и терминами из различных разделов математических дисциплин в сочетании с терминологией и многочисленными сведениями из естественнонаучных и инженерных дисциплин. Это обстоятельство создает при обучении трудности, в преодолении которых может помочь электронная информационносправочная система. Особенности разработки такой системы изложены в работе [12].

Хорошим примером использования информационно-коммуникационных технологий является мультимедийный курс лекций «Основы математического моделирования», читаемый автором для студентов кафедры «Прикладная математика» МГТУ имени Н.Э. Баумана. В рамках такого курса лекционные занятия проходят в специально оборудованных аудиториях, что позволяет показывать мультимедиа-презентации, использовать Интернет-ресурсы с помощью оборудования, подключаемого к беспроводным сетям передачи данных.

Внедрение информационнокоммуникационных технологий в учебный процесс повышает эффективность обучения, однако это достаточно сложная и трудоемкая работа, которая требует не только обширных познаний, но и использования современного оборудования и программного обеспечения.

Активное внедрение современных информационно-коммуникационных технологий в учебный процесс приводит к дальнейшему развитию информационно-образовательной среды, без которой сейчас уже сложно представить успешное проведение учебного процесса. 


\section{Организация учебных занятий}

Учебный план дисциплины «Основы математического моделирования» предусматривает проведение лекций и практических занятий. На лекциях студенты изучают методы построения математических моделей с нужными свойствами, способы качественного и количественного анализа построенных математических моделей, методики практической интерпретации результатов математического моделирования. На практических занятиях они разрабатывают математические модели, обоснованно выбирают способы анализа построенных математических моделей, обрабатывают и представляют результаты математического моделирования.

Закрепление полученных знаний, умений и навыков достигается при выполнении индивидуальных домашних заданий. Особенность их выполнения связана с разработкой иерархии математических моделей и анализом полученных моделей, по результатам которого можно сформулировать содержательные выводы, имеющие практическое значение.

Организация учебных занятий и система контроля результатов обучения должны создавать условия для объективной оценки полученных результатов, формировать у студентов мотивацию к систематической работе, повышать их состязательность в обучении и развивать способность самоконтроля результатов обучения.

\section{Индивидуальный подход}

Для осуществления индивидуального подхода в процессе обучения необходимо в течение всего семестра проводить мониторинг результатов обучения каждого студента, объективно оценивать уровень полученных знаний, приобретенных умений и навыков, отмечая при этом личностные качества и индивидуальные способности студента. Это позволяет принимать своевременные меры, направленные на повышение эффективности обучения, развитие личностных качеств и индивидуальных способностей студентов. Например, можно оказать помощь в адаптации студента к условиям учебного процесса, содействовать в осознанном выборе образовательной траектории, осуществить корректировку учебного материала индивидуально для каждого студента, предлагая ему дополнительные материалы для самостоятельного изучения.

Индивидуальный подход в процессе обучения повышает эффективность обучения, способствует развитию личностных качеств и индивидуальных способностей студентов, однако реализация индивидуального подхода предполагает обеспечение учебного процесса соответствующими средствами обучения и создание системы поощрения студентов.

\section{Выводы}

Исходя из вышеизложенного, можно сделать следующие выводы:

$\checkmark \quad$ при разработке содержания и структуры дисциплины «Основы математического моделирования» следует учитывать рекомендации, приведенные в работе [1];

$\checkmark$ заслуживает внимания единый подход к построению математической модели, которая в достаточной мере обладает нужными свойствами применительно к конкретному исследованию;

$\checkmark$ необходимо активное внедрение современных информационнокоммуникационных технологий в учебный процесс и дальнейшее развитие информационно-образовательной среды;

$\checkmark$ выполнение требований, предъявляемых к дисциплине «Основы математического моделирования», предполагает соответствующую организацию учебных занятий и объективную систему контроля результатов обучения;

$\checkmark$ рассмотренные особенности реализации индивидуального подхода способствуют повышению эффективности процесса обучения, развитию личностных качеств и индивидуальных способностей студентов.

\section{Заключение}

Таким образом, в статье изложены некоторые важные особенности, связанные с преподаванием учебной дисциплины «Основы математического моделирования», и сделаны содержательные выводы.

\section{References:}

1. Markelov GE (2015) Content of the Course «Fundamentals of Mathematical Modeling».
ISJ Theoretical \& Applied Science 05 (25): 5961. Soi: http://s-o-i.org/1.1/TAS*05(25)12 
2. Dym CL (2004) Principles of Mathematical Modeling. Elsevier Academic Press.

3. Glasgow LA (2014) Applied Mathematics for Science and Engineering. John Wiley \& Sons, Hoboken, N.J.

4. Heinz S (2011) Mathematical Modeling. Springer.

5. Meyer WJ (2004) Concepts of Mathematical Modeling. Dover Publ., Mineola, N.Y.

6. Myshkis AD (2014) Elements of the Theory of Mathematical Models [in Russian]. LIBROKOM, Moscow.

7. Samarskii AA, Mikhailov AP (2005) Mathematical Modeling: Ideas. Methods. Examples [in Russian]. FIZMATLIT, Moscow.

8. Velten K (2010) Mathematical Modeling and Simulation: Introduction for Scientists and Engineers. Wiley-VCH-Verl., Weinheim.
9. Zarubin VS (2010) Mathematical Modeling in Engineering [in Russian]. Izd-vo MGTU im. N.E. Baumana, Moscow.

10. Markelov GYe (2005) Basic Principles to Construct Mathematical Models. Vestnik MGTU im. N.E. Baumana. Ser. Estestvennye nauki, No. 4, pp. 59-70.

11. Markelov GE (2015) On Approach to Constructing a Working Mathematical Model. ISJ Theoretical \& Applied Science 04 (24): 287-290. Soi: http://s-oi.org/1.1/TAS*04(24)52 Doi: http://dx.doi.org/10.15863/TAS.2015.04.24.52

12. Zarubin VS, Markelov GE (2006) Features of the development of electronic informationreference system on mathematics for technical colleges. Uchenye zapiski, IIO RAO, Moscow, Iss. 19, pp. 196-197. 